\title{
GESTIÓN DEL CONOCIMIENTO EN PYMES: ¿QUÉ ASPECTOS CUENTAN?
}

\section{Pedro Sáenz Muñoz}

\section{RESUMEN}

El conocimiento es uno de los intangibles, quizá el más importante, sobre el que descansa la fuente de competitividad de las organizaciones en el siglo XXI. La revisión bibliográfica realizada con el objetivo de verificar la importancia que este elemento tiene para las Pymes y su concomitancia con otros aspectos organizacionales que pueden incidir en su adecuada gestión, permitieron constatar que: elementos de la propia gestión del conocimiento (las formas de adquirirlo, almacenarlo, transmitirlo y utilizarlo), la diversidad, características de las pymes asociadas a propiedad, dirección, estructura, cultura imperante y comportamiento, sistemas, procesos y procedimientos, recursos humanos, clientes y mercado merecen especial atención dado que están estrechamente ligados al eficiente uso del conocimiento organizacional.

El determinar si el impacto de estos elementos en la gestión del conocimiento es positivo o negativo puede ser determinado mediante estudios posteriores y enfocados a estos elementos.

Palabras Clave: Gestión del Conocimiento, Cultura, Diversidad. 